\title{
FIRST MOLECULAR DETECTION OF \\ BALL PYTHON NIDOVIRUS IN ITALY - SHORT COMMUNICATION
}

\author{
Elisa RAMPACCI ${ }^{{ }^{*}}$, Marco MASI ${ }^{2}$, Francesco Carlo ORIGGI ${ }^{3}$, Valentina STEFANETTI ${ }^{1}$, \\ Marco BotTINeLLI ${ }^{1}$, Paolo Selleri ${ }^{2}$, Mauro Coletti ${ }^{1}$ and Fabrizio PASSAMOnTI ${ }^{1}$ \\ ${ }^{1}$ Department of Veterinary Medicine, University of Perugia, San Costanzo 4, 06126, \\ Perugia, Italy; ${ }^{2}$ Centro Veterinario Specialistico, Rome, Italy; ${ }^{3}$ Department of Infectious \\ Diseases and Pathobiology, Centre for Fish and Wildlife Health, University of Bern, \\ Bern, Switzerland
}

(Received 17 May 2018; accepted 20 November 2018)

A retrospective study was conducted to investigate the presence of ferlavirus, ball python nidovirus and bacteria in 32 tracheobronchial lavages from ball pythons raised in captivity and affected by respiratory disease. A touchdown reverse transcription polymerase reaction (RT-PCR) was performed to detect ball python nidovirus RNA targeting a 260-bp portion of the ORF1a gene, while a nested RT-PCR was applied to identify RNA targeting the 518-bp ferlavirus partial L gene. RT-PCR positive products were submitted for Sanger's sequencing and phylogeny reconstruction. Bacteriological examinations were performed to diagnose a possible bacterial involvement. BLAST analysis revealed that the nucleotide sequences of the six (18.8\%) RT-PCR positive amplicons were $90-97 \%$ identical to the partial sequence of the ORF1a gene of the recently described ball python nidovirus. All tested snakes were negative for ferlavirus. Thirteen out of 32 samples $(40.6 \%)$ were bacteriologically positive. Respiratory tract diseases can be a substantial problem for snake breeders, considering the rapid transmission of respiratory pathogens. The results and published studies show that ball python nidovirus is circulating in python collections and could be linked to suboptimal management practices. Surveillance programs are desirable as part of the routine snake health assessment. Tracheobronchial lavage is a fast, practical, cost-effective procedure for sample collection.

Key words: Ball python nidovirus, ferlavirus, respiratory disease, RT-PCR, phylogeny reconstruction

Respiratory diseases are among the most common causes of morbidity and mortality in captive snake collections. Suboptimal management practices contribute to immunosuppressive conditions favouring the occurrence of disease, while high population density and exchange at animal shows may facilitate the

*Corresponding author; E-mail: elisa.rampacci@gmail.com;

Phone: 0039 (075) 585-7720; Fax: 0039 (075) 585-7662 
transmission of pathogens (Stenglein et al., 2014). Gram-negative aerobic bacteria are more commonly associated with pneumonia (Mayer and Frank, 1974; Jacobson, 1984; Schmidt et al., 2013), while viruses belonging to the genus Ferlavirus within Paramyxoviridae have been reported as frequent viral pathogens diagnosed in the course of respiratory disease in snakes, e.g. Pythonidae (Schmidt et al., 2013). A disease characterised by lung pathology (proliferative interstitial pneumonia), stomatitis, tracheitis, and oesophagitis is associated with a novel nidovirus in snakes, which currently appears to be overrepresented in ball pythons (Python regius) (Bodewes et al., 2014; Stenglein et al., 2014; Uccellini et al., 2014). The order Nidovirales comprises human and animal pathogens, including the recently discovered, tentatively-named bovine nidovirus (Tokarz et al., 2015) associated with respiratory disease and related to the ball python nidovirus, both belonging to an unassigned genus within the subfamily Torovirinae, family Coronaviridae of the Nidovirales order. Experimental infections have confirmed the cause-and-effect relationship between ball python nidovirus infection and upper respiratory tract inflammation with cranial oesophagus involvement and progression to proliferative interstitial pneumonia (Hoon-Hanks et al., 2018). The highest viral load appears to be detected in the respiratory tract of the infected snakes, where the viral load is up to five times higher than in other tissues (Bodewes et al., 2014; Stenglein et al., 2014). Additionally, recent findings support the collection of tracheobronchial lavage for the aetiological diagnosis of respiratory diseases (Schmidt et al., 2013; Pees et al., 2016). Accordingly, this work was aimed at retrospectively investigating the detection of ball python nidovirus, ferlavirus, and bacterial pathogens in tracheobronchial lavages collected throughout Italy from captive ball pythons exhibiting respiratory signs.

The retrospective study was conducted on tracheobronchial lavages belonging to 32 ball pythons and submitted to an Italian diagnostic laboratory in 2017 for microbial examinations. Sample records were reviewed to acquire anamnestic data and results of the diagnostic examinations. For this investigation, it was decided to select tracheobronchial lavages on the basis of sample homogeneity and more sensitive pathogen detection, as suggested by others (Marschang and Kolesnik, 2017). RNA was extracted from pelleted tracheobronchial lavages using Ambion PureLink RNA extraction kit (Thermo Fisher Scientific, USA) in accordance with the manufacturer's instructions. Prior to performing the reverse transcriptase-polymerase chain reaction (RT-PCR) assay, extracted RNA was quantified using a NanoDrop spectrophotometer. RT-PCR was carried out to detect ball python nidovirus RNA targeting a portion of ORF1a (Stenglein et al., 2014) using the following primer sequences: MDS- $481 \mathrm{w}$ (GCTCSAAGACAA CCCAGAAG) and MDS-482 (TTGCTGCGATGATACCTTTG). The experimental setup was proposed by Marschang and Kolesnik (2017). Briefly, RNA was reverse transcribed for $15 \mathrm{~min}$ at $50^{\circ} \mathrm{C}$ and denatured for $7 \mathrm{~min}$ at $95^{\circ} \mathrm{C}$. Subsequently, the $50 \mu \mathrm{L}$ mix underwent nine touchdown cycles at $95{ }^{\circ} \mathrm{C}$ for 
$10 \mathrm{sec}$, at $57.5^{\circ} \mathrm{C}$ for $30 \mathrm{sec}\left(-1{ }^{\circ} \mathrm{C}\right.$ per cycle), and at $72{ }^{\circ} \mathrm{C}$ for $50 \mathrm{sec}$ and 26 cycles at $95{ }^{\circ} \mathrm{C}$ for $10 \mathrm{sec}$, at $49.5^{\circ} \mathrm{C}$ for $30 \mathrm{sec}$, and at $72^{\circ} \mathrm{C}$ for $50 \mathrm{sec}$. The final extension was carried out at $72{ }^{\circ} \mathrm{C}$ for $7 \mathrm{~min}$. A nested RT-PCR protocol was performed to detect ferlavirus RNA according to a published method targeting a 518-bp part of the L gene (Ahne et al., 1999). Following the reverse transcription, cDNA was denatured for 3 min at $95^{\circ} \mathrm{C}$ and amplified 30 times at $95^{\circ} \mathrm{C}$ for $30 \mathrm{sec}$ (denaturation), followed by $30 \mathrm{sec}$ at $45^{\circ} \mathrm{C}$ (annealing) and $1 \mathrm{~min}$ at $72{ }^{\circ} \mathrm{C}$ (extension) with a final 10 -min period at $72^{\circ} \mathrm{C}$. The cycling protocol of the nested steps was identical to the first run of PCR amplification. In each set of reactions, negative and positive controls of nucleic acids extracted from nidovirus (Laboklin, Germany) or ferlavirus disease were tested in parallel to validate the assays. A $10-\mu \mathrm{L}$ aliquot of PCR products was resolved in a $2 \%$ agarose gel. Positive PCR amplification products were purified using Wizard SV Gel and PCR Clean-Up System kit (Promega, USA) following the manufacturer's instructions and submitted for Sanger sequencing. Finally, the obtained sequences were submitted to BLAST analysis to conclusively assess the nature of the amplified product. The RT-PCR targeting the 518-bp ferlavirus partial L gene was negative for all samples, while six expected size amplicons ( $260 \mathrm{bp}$ ) were detected by performing touchdown RT-PCR for ball python nidovirus. The obtained sequences confirmed that 6/32 samples (18.8\%) were nidovirus positive, having 90-97\% identity to the homologous ORF1a gene partial sequence of the ball python nidovirus (GenBank accession number, KJ541759.1). The novel sequences have been submitted to GenBank and assigned the accession numbers MH854563MH854568. These sequences were 95-99\% identical to each other and 93-97\% identical to the positive control. The obtained sequences together with those of the positive control were used for the phylogenetic analysis together with 19 published nidoviral sequences identified by the accession numbers KU215836KU215854 (Marschang and Kolesnik, 2017), the homologous parts of the nidoviral genomes KJ541759 (Stenglein et al., 2014), KJ935003 (Bodewes et al., 2014), MF351889 (Dervas et al., 2017), MG752895 (Hoon-Hanks et al., 2018) and the outgroup Shingleback nidovirus KX184715 (O'Dea et al., 2016). The sequences were first aligned using ClustalW software. The obtained alignment was then used to calculate a Maximum Likelihood phylogenetic tree using the Mega 7 software with the default parameters (Tamura and Nei, 1993). For bacteriological examination, each tracheobronchial lavage was inoculated onto $5 \%$ sheep blood, McConkey, Mannitol Salt, and Sabouraud agar. Enrichment was carried out in Rappaport Vassiliadis soy broth, and subsequent inoculation onto Hektoen Enteric agar was performed to detect Salmonella spp. Inoculated plates were incubated aerobically at $37^{\circ} \mathrm{C}$ for $24-48 \mathrm{~h}$. Sabouraud agar plates were incubated for at least 5 days for mycological examination. The identification of bacteria was performed according to colony morphology, Gram staining, biochemical tests, and commercially available API kit results. 


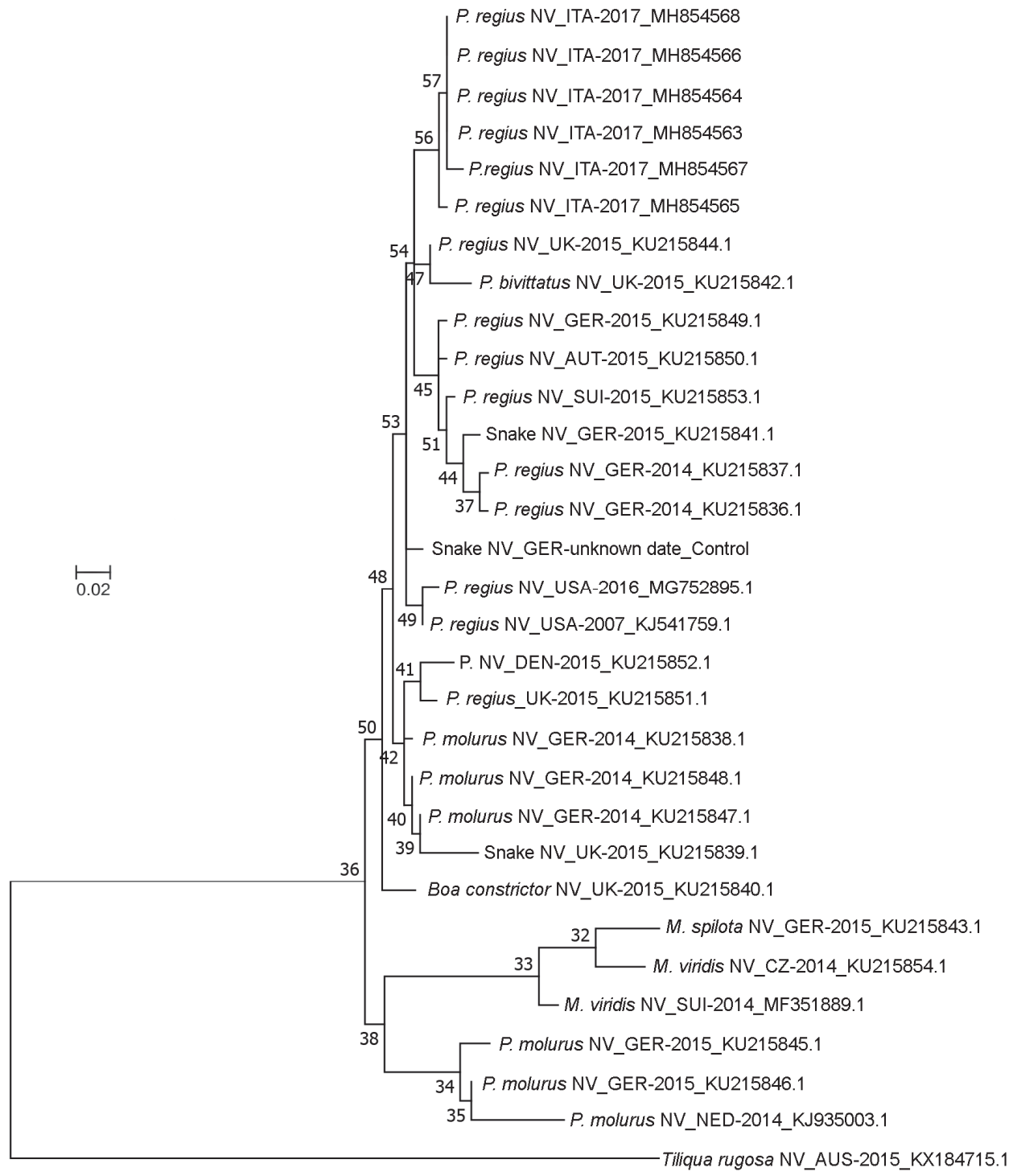

Fig. 1. Molecular phylogenetic analysis by Maximum Likelihood method. A total of 31 nidoviral sequences were analysed including the six detected in this investigation together with the sequence used as positive control, 19 published sequences of the polyprotein 1a, the homologous parts of sequenced genomes and the outgroup Shingleback nidovirus. Sequence labelling details the source as reported in GenBank. Close clustering of the novel sequences, supported by convincing bootstrap values, are observed. Abbreviations: AUS, Australia; AUT, Austria; CZ, Czech Republic;

DEN, Denmark; GER, Germany; ITA, Italy; M, Morelia; NED, The Netherlands; NV, nidovirus; P, Python; SUI, Switzerland; UK, United Kingdom 
Tracheobronchial lavages belonged to ball pythons between 2 and 6 years of age. Twenty-five were females and seven were males. All animals exhibited respiratory signs at the time of sampling, including serous-to-purulent discharge from the nostrils with exudate collection in the oral cavity, periorbital abscesses, cloudy tracheal wash samples with white-yellow clumps, tachypnoea, gasping, and severe laboured breathing. Additionally, stomatitis was recorded in 14 of 32 samples (43.8\%). Snakes belonged to five different breeding centres throughout Italy. Four of the five breeding facilities were characterised by good practices in management and hygiene, whereas ball pythons from the fifth facility were housed in suboptimal conditions with elevated levels of environmental ammonia. This breeding centre was a large-scale snake breeding facility with an established international trade arrangement. As detailed in Fig. 1, the sequences MH854563, 64, 66 and 68 clustered together, showing very high similarities. The novel sequences appear to be more closely related to one of the groups of nidoviral sequences previously published and isolated from Pythonidae in the United Kingdom, Austria, Germany and Switzerland. The animals that tested positive were all from the breeding centre with the highest density of subjects. Five out of the six ball python nidovirus positive snakes had stomatitis (83.3\%). Thirteen out of 32 samples $(40.6 \%)$ were bacteriologically positive. Pure cultures were obtained from all of the positive samples (Table 1). Four out of the six ball pythons that tested positive for ball python nidovirus were positive for Aeromonas hydrophila $(2 / 6 ; 33.3 \%)$, Pseudomonas aeruginosa $(1 / 6 ; 16.7 \%)$, and Stenotrophomonas maltophilia $(1 / 6 ; 16.7 \%)$. Positive bacteriological examinations correlated with severe respiratory signs, including the presence of a thick mucous discharge. Additionally, eight $(57.1 \%)$ of the tracheobronchial lavages of snakes affected by stomatitis yielded bacterial isolates. No fungal isolates were detected.

Table 1

Percentage of bacterial isolates from tracheobronchial lavages of ball pythons

\begin{tabular}{lc}
\hline Microbial isolates & Isolation percentage (\%) \\
\hline Stenotrophomonas maltophilia & $15.6 \%(5 / 32)$ \\
Aeromonas hydrophila & $12.5 \%(4 / 32)$ \\
Pseudomonas aeruginosa & $9.4 \%(3 / 32)$ \\
Staphylococcus spp. & $3.1 \%(1 / 32)$ \\
\hline
\end{tabular}

Respiratory infectious disease can be a substantial problem for snake breeders when also considering the rapid transmission of respiratory pathogens. For these reasons, dissemination data are necessary to better understand the scope of the problem. Ferlavirus is a common agent infecting the respiratory tract of snakes (Jacobson et al., 1981; Jacobson et al., 1992; Schmidt et al., 2013). However, all ball pythons tested in this work were negative for ferlavirus, in spite of 
the fact that tracheobronchial lavage is considered the sample of choice for ferlavirus detection in snakes (Schmidt et al., 2013). Such a result could indicate negligible virus circulation in Italy; however, a large-scale epidemiological research should be conducted to validate these data. Overall, we observed a ball python nidovirus prevalence of $18.8 \%$; however, all positive animals belonged to a single breeding centre, which was characterised by the highest density of animals and extensive trade activity that could have facilitated viral transmission. German researchers reported a ball python nidovirus prevalence of $14.9 \%$ among tested snakes from different families. Eighty-six per cent of the positive snakes were Pythonidae (Marschang and Kolesnik, 2017). This finding suggests a putative predisposition or higher sensitivity of this taxon to nidovirus-associated respiratory diseases. The bacteria isolated in this investigation were listed among the bacteria found in the oral cavities and glottal swabs of healthy snakes (Goldstein et al., 1981; Hilf et al., 1990; Hejnar et al., 2007). Therefore, the actual cause of respiratory disorders affecting the ball pythons examined in the present study might not be primarily associated with bacterial agents; however, bacteria belonging to the microbial flora of healthy subjects appear to be facultative causes of respiratory infections (Schmidt et al., 2013). In this study, four out of six (66.7\%) ball python nidovirus-positive animals had bacteriologically positive tracheobronchial lavages. Viral infections contribute to host immunosuppression, and thus favour secondary clinical diseases associated with facultative bacterial pathogens (Orós et al., 2001). The limited sample size did not allow us to define the actual nature of the virus-bacteria relationship but the hypothesis that commensal bacterial species may complicate the respiratory disorders potentially caused by ball python nidovirus cannot be completely ruled out. Of the tracheobronchial lavages from ball pythons affected with clinically diagnosed stomatitis, $57.1 \%$ were bacteriologically positive, which is consistent with the previously reported association between stomatitis and pneumonia (Schmidt et al., 2013; Hoon-Hanks et al., 2018), potentially due to bacteria descending from stomatitis to the lower respiratory tract. To conclude, tracheobronchial lavage is a fast, practical, cost-effective procedure for sample collection, which could be considered a useful tool to set surveillance programs and facilitate the early viral and bacterial diagnoses; however, limitations include the possibility of false-negative results in cases of viraemia that are not associated with viral shedding. This study represents the first investigation conducted in Italy on infectious agents involved in respiratory diseases of ball pythons. Nevertheless, further research is recommended to increase our understanding on the dissemination of respiratory infectious agents among snake populations. 


\section{Acknowledgements}

We are particularly grateful to Dr. Rachel Marschang (Laboklin, Germany) for providing the nidovirus-positive control needed to realise this study. Additionally, the authors are pleased to acknowledge Gianluca Alunni for his valuable technical assistance and constructive suggestions during the development of this research.

\section{References}

Ahne, W., Batts, W. N., Kurath, G. and Winton, J. R. (1999): Comparative sequence analyses of sixteen reptilian paramyxoviruses. Virus. Res. 63, 65-74.

Bodewes, R., Lempp, C., Schürch, A. C., Habierski, A., Hahn, K., Lamers, M., von Dörnberg, K., Wohlsein, P., Drexler, J. F., Haagmans, B. L., Smits, S. L., Baumgärtner, W. and Osterhaus, A. D. M. E. (2014): Novel divergent nidovirus in a python with pneumonia. J. Gen. Virol. 95, 2480-2485.

Dervas, E., Hepojoki, J., Laimbacher, A., Romero-Palomo, F., Jelinek, C., Keller, S., Smura, T., Hepojoki, S., Kipar, A. and Hetzel, U. (2017): Nidovirus-associated proliferative pneumonia in the Green Tree Python (Morelia viridis). J. Virol. 91, e00718-17.

Goldstein, E. J., Agyare, E. O., Vagvolgyi, A. E. and Halpern, M. (1981): Aerobic bacterial oral flora of garter snakes: development of normal flora and pathogenic potential for snakes and humans. J. Clin. Microbiol. 13, 954-956.

Hejnar, P., Bardon, J., Sauer, P. and Kolár, M. (2007): Stenotrophomonas maltophilia as a part of normal oral bacterial flora in captive snakes and its susceptibility to antibiotics. Vet. Microbiol. 121, 357-362.

Hilf, M., Wagner, R. A. and Yu, V. L. (1990): A prospective study of upper airway flora in healthy boid snakes and snakes with pneumonia. J. Zoo Wildl. Med. 21, 318-325.

Hoon-Hanks, L. L., Layton, M. L., Ossiboff, R. J., Parker, J. S. L., Dubovi, E. J. and Stenglein, M. D. (2018): Respiratory disease in ball pythons (Python regius) experimentally infected with ball python nidovirus. Virology $\mathbf{5 1 7}, \mathbf{7 7 - 8 7 .}$

Jacobson, E., Gaskin, J. M., Page, D., Iverson, W. O. and Johnson, J. W. (1981): Illness associated with paramyxo-like virus infection in a zoologic collection of snakes. J. Am. Vet. Med. Assoc. 179, 1227-1230.

Jacobson, E. R. (1984): Biology and diseases of reptiles. In: Fox, J. G., Cohen, B. and Lowe, F. (eds) Laboratory Animal Medicine, Academic Press, New York. pp. 449-476.

Jacobson, E. R., Gaskin, J. M., Wells, S., Bowler, K. and Schumacher, J. (1992): Epizootic of ophidian paramyxovirus in a zoological collection: pathological, microbiological, and serological findings. J. Zoo Wildl. Med. 23, 318-327.

Marschang, R. E. and Kolesnik, E. (2017): Detection of nidoviruses in live pythons and boas. Tierarztl. Prax. Ausg. K. Kleintiere Heimtiere 45, 22-26.

Mayer, H. and Frank, W. (1974): Bacteriological investigations on reptiles and amphibians [in German]. Zentralbl. Bakteriol. Orig. A 229, 470-481.

O’Dea, M. A., Jackson, B., Jackson, C., Xavier, P. and Warren, K. (2016): Discovery and partial genomic characterization of a novel nidovirus associated with respiratory Disease in wild Shingleback Lizards (Tiliqua rugosa). PLoS One. 11, e0165209.

Orós, J., Sicilia, J., Torrent, A., Castro, P., Déniz, S., Arencibia, A., Jacobson, E. R. and Homer, B. L. (2001): Immunohistochemical detection of ophidian paramyxovirus in snakes in the Canary Islands. Vet. Rec. 149, 21-23. 
Pees, M., Neul, A., Müller, K., Schmidt, V., Truyen, U., Leinecker, N. and Marschang, R. E. (2016): Virus distribution and detection in corn snakes (Pantherophis guttatus) after experimental infection with three different ferlavirus strains. Vet. Microbiol. 182, 213-222.

Schmidt, V., Marschang, R. E., Abbas, M. D., Ball, I., Szabo, I., Helmuth, R., Plenz, B., Spergser, J. and Pees, M. (2013): Detection of pathogens in Boidae and Pythonidae with and without respiratory disease. Vet. Rec. 172, 236.

Stenglein, M. D., Jacobson, E. R., Wozniak, E. J., Wellehan, J. F. X., Kincaid, A., Gordon, M., Porter, B. F., Baumgartner, W., Stahl, S., Kelley, K., Towner, J. S. and DeRisi, J. L. (2014): Ball python nidovirus: a candidate etiologic agent for severe respiratory disease in Python regius. $\mathrm{mBio}$ 5, $\mathrm{e} 01484-01414$.

Tamura, K. and Nei, M. (1993): Estimation of the number of nucleotide substitutions in the control region of mitochondrial DNA in humans and chimpanzees. Mol. Biol. Evol. 10, 512-526.

Tokarz, R., Sameroff, S., Hesse, R. A., Hause, B. M., Desai, A., Jain, K. and Lipkin, W. I. (2015): Discovery of a novel nidovirus in cattle with respiratory disease. J. Gen. Virol. 96, 2188-2193.

Uccellini, L., Ossiboff, R. J., de Matos, R. E. C., Morrisey, J. K., Petrosov, A., Navarrete-Macias, I., Jain, K., Hicks, A. L., Buckles, E. L., Tokarz, R., McAloose, D. and Lipkin, W. I. (2014): Identification of a novel nidovirus in an outbreak of fatal respiratory disease in ball pythons (Python regius). Virol. J. 11, 144. 